\section{Serial position effects in humans and animals: A reply to Gaffan}

\author{
WILLIAM A. ROBERTS \\ and PHILIPP J. KRAEMER \\ University of Western Ontario, London, Ontario, Canada
}

Gaffan (1983) argues that there is only weak evidence for Roberts and Kraemer's (1981) contention that the primacy effect may be a general characteristic of primate memory. He considers our conclusion in the larger context of his own research and points out that he has reported several failures to find a primacy effect in list memory experiments with monkeys. Our position clearly needs clarification. We considered our data and those of Sands and Wright $(1980 \mathrm{a}, 1980 \mathrm{~b})$ in the still broader context of comparative research. We found it notable that researchers in different laboratories, using different species of monkeys, different stimuli, and different procedures, had been able to produce reliable primacy effects in monkeys. At the time our paper was written, no primacy effects had been found for retention of once-presented lists in pigeons (MacPhail, 1980; Shimp, 1976; Shimp \& Moffitt, 1974), rats (Roberts \& Smythe, 1979), or a dolphin (Thompson \& Herman, 1977). Our intention, then, was to indicate that primacy effects were reliably demonstrable in human and nonhuman primates but had not been demonstrated in nonprimate species. It was not our intention to imply that primacy effects had been found in every list memory experiment done with monkeys, any more than we would claim that every list memory experiment with humans shows a primacy effect. Gaffan's claim that a primacy effect may be found in monkeys only under certain experimental conditions should be acknowledged, but it does not detract from the fact that production of a primacy effect now can be generalized from human to nonhuman primates.

Given that a primacy effect now has been demonstrated under certain conditions with monkeys, we may entertain theoretical accounts of this effect. Gaffan (1983) advances the hypothesis that monkeys in the Roberts and Kraemer (1981) and Sands and Wright $(1980 \mathrm{a}, 1980 \mathrm{~b})$ experiments attended more to the initial item of a list than to the following items and that the primacy effects they observed were a consequence of better memory for more highly attended items. The initial stimulus was attended to more strongly because a response was required to introduce this stimulus but not the remainder of the list. In his experiments, monkeys had to respond to produce each list item, and no primacy effects were found. It is suggested that item presentation contingent on a subject's response maintains attention and high retention for all items on a list.

We too have considered the possible importance of attentional processes in the primacy effects seen in our monkeys, and we continue to do so. However, there are some problems with the position advocated by Gaffan (1983). Gaffan says nothing about the recency effect. Both Roberts and Kraemer (1981) and Sands and Wright (1980a, 1980b) found an increase in retention for items at the end of a list. Why should retention improve for terminal items (often to a level higher than that for the initial item) if all items beyond the first one are poorly attended? In the Roberts and Kraemer experiments, list lengths of three and six items were randomly intermixed, with twice as many six-item lists as three-item lists. Animals could not predict whether the third item presented in a list would be in the middle of a six-item list or at the end of a three-item list. Yet, the same item was poorly retained when tested as Position 3 in a sixitem list and better retained when tested as the final item of a three-item list. If this item was poorly attended to in both cases, why was it better remembered in the three-item list than in the six-item list?

Finally, let us consider research with nonprimate species. Shimp (1976) required pigeons to peck a key designating the correct position of each item in a three-item list, and Roberts and Smythe (1979) required rats to enter each of the alleys that made up a seven-item list. Since animals responded to each item of the list in both cases, Gaffan's response-dependent attentional hypothesis suggests that consistently high retention should be found at all serial positions. Instead, marked declines in performance were seen from the ends of the lists to the beginnings.

Although attentional processes certainly may be important in memory experiments, it seems unlikely that response-generated attention can account for the variety of serial position effects seen in monkeys and other animals. There seems to be substantial evidence that the position of items in a list exerts strong effects on retention when the presentation of items is both response dependent and response independent.

\section{REFERENCES}

GafFan, D. A comment on primacy effects in monkeys' memory for lists. Animal Learning \& Behavior, 1983, 11, 144-145.

MACPhaIL, E. M. Short-term visual recognition memory in pigeons. Quarterly Journal of Experimental Psychology, 1980, 32, $521-538$.

Roberts, W. A., \& Kraemer, P. J. Recognition memory for lists of visual stimuli in monkeys and humans. Animal Learning \& Behavior, 1981, 9, 587-594.

Roberts, W. A., \& Smythe, W. E. Memory for lists of spatial events in the rat. Learning and Motivation, 1979, 10, 313-336. 
Sands, S. F., \& Wriaht, A. A. Primate memory: Retention of serial list items by a rhesus monkey. Science, 1980, 209, 938-939. (a)

SAnd8, S. F., \& Wright, A. A. Serial probe recognition performance by rhesus monkey and a human with 10- and 20item lists. Journal of Experimental Psychology: Animal Behavior Processes, 1980, 6, 389-396. (b)

SkImp, C. P. Short-term memory in the pigeon: Relative recency. Journal of the Experimental Analysis of Behavior, 1976, 25, 55-61.
Shimp, C. P., \& Moffit, M. Short-term memory in the pigeon: Stimulus-response associations. Journal of the Experimental Analysis of Behavior, 1974, 22, 507-512.

Thompron, R. K. R., \& Herman, L. M. Memory for lists of sounds by the bottle-nosed dolphin: Convergence of memory processes with humans? Science, 1977, 195, 501-503.

(Manuscript received July 25, 1982; accepted for publication August 21, 1982.) 